\title{
Fucoidans Stimulate Immune Reaction and Suppress Cancer Growth
}

\author{
VACLAV VETVICKA and JANA VETVICKOVA
}

University of Louisville, Department of Pathology, Louisville, KY, U.S.A.

\begin{abstract}
Background/Aim: Fucoidans are gaining popularity as natural immunomodulators. The aim of this study was to compare the immunological activities or both purified samples and commercially available mixtures containing fucoidan. Materials and Methods: We evaluated the effects of various samples on phagocytosis, mitogenic response, natural killer (NK) activity, antibody formation and inhibition of breast cancer growth. Results: We found significant immunostimulating activity, but the strength of these effects was different among individual samples. Conclusion: Fucoidans have strong immunostimulating potential, including inhibition of cancer, with isolated samples offering better activity than commercial mixtures.
\end{abstract}

Fucoidan is a complex sulfated polysaccharide consisting of sulfated fucose residues and found mostly in brown marine algae, echinoderms (1) and seagrasses (2). Fucoidans exhibit numerous biological activities found both in in vitro and in vivo experiments. Fucoidan extracts have been found to ameliorate acute colitis (3), have anticancer activity (4) mediate via natural killer (NK) cells (5) and affect inflammation, vascular physiology, as well as oxidative stress $(6,7)$. Some effects differ based on the type of extract, as documented by the differential effects of high and low molecular weight fucoidans on the severity of arthritis in mice. The low molecular weight samples reduced arthritis via suppression of Th1-mediated immunity, whereas high molecular weight samples enhanced the inflammatory activation of macrophages (8). Subsequent experiments revealed that high molecular weight fucoidans stimulated spleen cells, whereas low

This article is freely accessible online.

Correspondence to: Vaclav Vetvicka, Ph.D., University of Louisville, Department of Pathology, 511 South Floyd Street, Louisville, KY 40202, U.S.A. Tel: +1 5028521612, Fax: +1 5028521177, e-mail: vaclav.vetvicka@louisville.edu

Key Words: Natural immunity, cancer, phagocytosis, polysaccharide. molecular weight samples had little activity or were toxic (9). The reasons for these differences are still unknown. Using a fish model, however, dietary fucoidan was found to influence blood chemistry and constituents, antioxidation and innate immunity (10). In human models, fucoidan delayed apoptosis and induced proinflammatory cytokines, probably via activation of the PI3K/AKT pathway (11). As fucoidan can function as an adjuvant and stimulate antibody response (12), it has been used to improve vaccine efficacy (13).

Cancer development is the most studied effect of fucoidan. The mechanisms are still unknown. However, fucoidan can directly induce cytotoxicity and apoptosis of cancer cells (14) probably explained by an additional study suggesting implication of macrophages and blood leukocytes in relation to fucoidan (15).

In our study, we not only directly compared the biological activities of individual fucoidan samples, but also compared purified samples with commercially available component mixtures. Thus, our study answers the question not only whether fucoidans influence immune reactions, but also if the popular idea of combining biologically active molecules together improves their effectiveness.

\section{Materials and Methods}

Materials. Individual samples were purchased from the manufacturers or distributors as shown in Table I. RPMI 1640 medium, sodium citrate, 4-(2-hydroxyethyl)-1-piperazine-ethanol-sulfonic acid (HEPES), antibiotics, Wright stain, Freund's adjuvant, ovalbumin, Concanavalin A (Con A) and lipopolysaccharide (LPS) were purchased from Sigma (St. Louis, MO, USA). Fetal calf serum (FCS) was from Hyclone Laboratories (Logan, UT, USA).

Cells. J774A.1 mouse macrophages and YAC cells were obtained from the ATCC (Manassas, VA, USA). The BALB/c mouse-derived mammary tumor cell line Ptac64 was generously provided by Dr. Wei-Zen Wei of the Michigan Cancer Foundation, Wayne State University, Detroit, MI, USA. The cell lines were maintained in RPMI 1640 medium containing HEPES buffer supplemented with $10 \%$ heat-inactivated FCS, $100 \mathrm{U} / \mathrm{ml}$ penicillin and $100 \mu \mathrm{g} / \mathrm{ml}$ streptomycin, in plastic disposable tissue culture flasks at $37^{\circ} \mathrm{C}$ in a $5 \% \mathrm{CO}_{2} / 95 \%$ air incubator. 
Table I. Detailed information on samples used in this study.

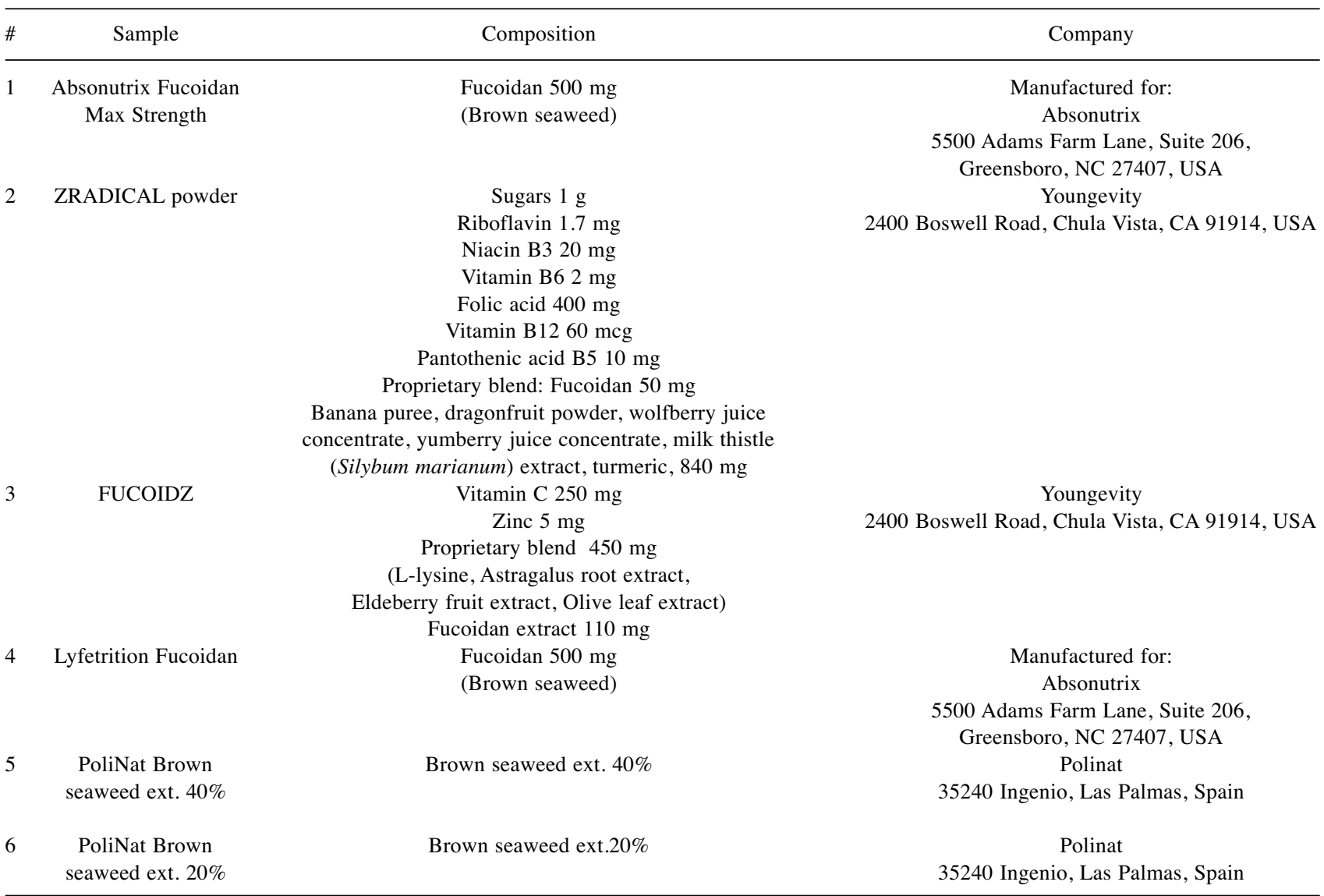

Animals. Female, 8-week-old BALB/c mice were purchased from the Jackson Laboratory (Bar Harbor, ME, USA). All animal work was performed according to the University of Louisville Institutional Animal Care and Use Committee (IACUC) protocol. Animals were sacrificed by cervical dislocation.

Phagocytosis. The technique employing phagocytosis of synthetic polymeric microspheres was described in Vetvicka et al. $(16,17)$. Briefly, peripheral blood cells were incubated in vitro with $0.05 \mathrm{ml}$ of 2-hydroxyethyl methacrylate particles (HEMA; $5 \times 10^{8} / \mathrm{ml}$ ). The test tubes were incubated at $37^{\circ} \mathrm{C}$ for $60 \mathrm{~min}$, with intermittent shaking. Smears were stained with Wright stain. Cells with three or more HEMA particles were considered positive. Mice were injected intraperitoneally with individual samples or phosphate-buffered saline (PBS; control). All experiments were performed in triplicate. At least 200 cells in 60 high-power fields were examined in each experiment. In in vitro experiments, cells were incubated with 0.01 $\mathrm{ml}$ of HEMA particles/well. Incubation and staining was identical to in vivo experiments.

Mitogenic response assay. For the mitogenic response assay, splenic lymphocytes $\left(5 \times 10^{5}\right.$ per well) were co-cultured with tested samples $(10 \mu \mathrm{g})$ and either $10 \mu \mathrm{g}$ of Con A or $1 \mu \mathrm{g}$ of LPS in $200 \mu \mathrm{l}$ of
RMPI 1640 plus $10 \%$ FCS for 72 h. Proliferation was evaluated using the Biotrak cell proliferation ELISA system (GE Healthcare Bio-Sciences, Pittsburg, PA, USA).

In vitro cytotoxicity assay. Spleen cells were isolated from mice by standard methods. Cell suspension was generated by pressing minced spleen against the bottom of a petri dish containing PBS. After erythrocyte elimination by 10 -second incubation in distilled water and five washes in cold PBS, cells were re-suspended in PBS and counted. Viability was determined by Trypan blue exclusion. Only cells with viability better than $95 \%$ were used in subsequent experiments. Splenocytes $\left(10^{6} / \mathrm{ml} ; 0.1 \mathrm{ml} /\right.$ well $)$ in V-shaped 96 -well microplates were incubated with individual samples $(2 \mu \mathrm{g} / \mathrm{ml})$ for $30 \mathrm{~min}$ at $37^{\circ} \mathrm{C}$ and then washed three times with RPMI 1640 medium. After washing, $50 \mu \mathrm{l}$ of target cell line YAC-1 (two different concentrations of target cells were used so the final effectortarget ratio was $32: 1$ and $64: 1$, respectively). After spinning the plates at $250 \times g$ for $5 \mathrm{~min}$, the plates were incubated for $4 \mathrm{~h}$ at $37^{\circ} \mathrm{C}$. The cytotoxic activity of cells was determined by the use of CytoTox 96 Non-Radioactive Cytotoxicity Assay from Promega (Promega, Madison, WI, USA), according to the manufacturer's instructions. Briefly, $10 \mu \mathrm{l}$ of lysis solution was added into the appropriate control wells $45 \mathrm{~min}$ before the end of incubation. The next step was to spin 


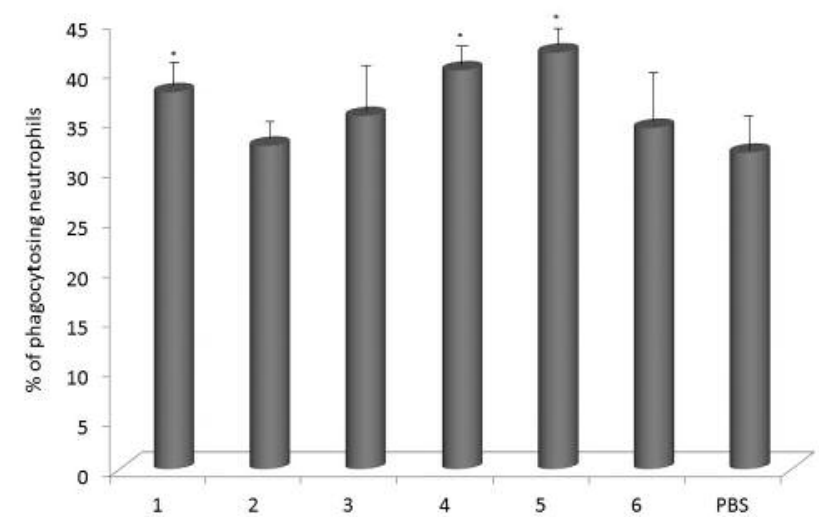

Figure 1. Effects on phagocytosis by peripheral blood monocytes by orally administered individual samples against phosphate-buffered saline $(P B S)$. Each value represents the mean $\pm S D$. *Represents significant differences between control (PBS) and tested samples at $p \leq 0.05$ level. All experiments were performed in triplicate.

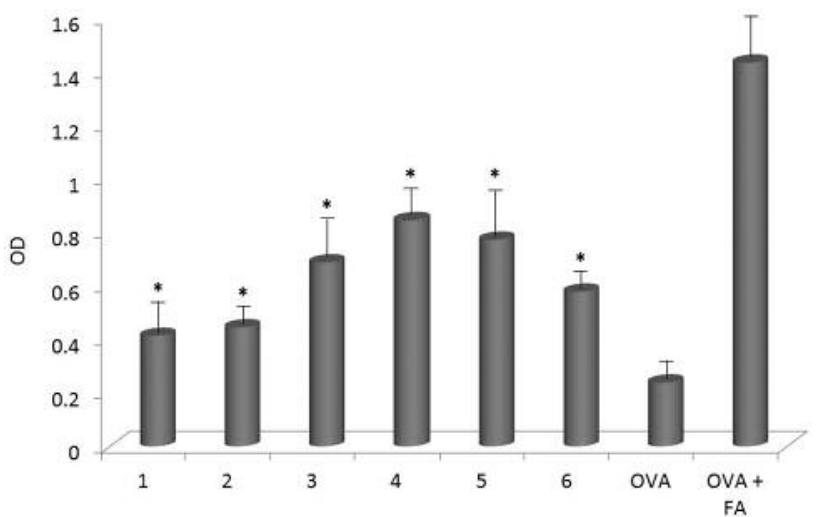

Figure 2. Effects on formation of antibodies against ovalbumin (OVA) by orally administered individual samples. Animals were injected twice (two weeks apart) with antigen. The serum was collected 7 days after last injection. Level of specific antibodies against ovalbumin was detected by ELISA. As positive control, Freund's adjuvant (FA) was used. *Represents significant differences between control (OVA alone) and samples at $p \leq 0.05$ level.

groups. Experimental treatment was achieved by intraperitoneal injections of tested samples diluted in PBS (once/day for 14 days). After treatment, the mice were sacrificed, tumors removed and weighed (18).

\section{Results}

The list of individual samples of purified fucoidans and various commercially available mixtures is given in Table I. The purpose was to directly compare the effects of laboratory and commercial samples. In each case, the doses of fucoidan used in experiments were calculated from the information given by the manufacturer.

As fucoidans can influence phagocytosis of blood leukocytes, the study of such a process seemed imperative. As summarized in Figure 1, only samples \#1, \#4 and \#5 showed significant stimulation of phagocytosis of HEMA microspheres. A different situation was found when the antibody response was tested. Using OVA as an antigen, all samples significantly increased specific antibody response compared to antigen alone. However, none of the samples reached the levels of antigen and adjuvant (Figure 2).

Subsequently, proliferation of $\mathrm{T}$ and $\mathrm{B}$ lymphocytes after mitogenic stimulation was measured. The dose of 10 $\mu \mathrm{g}$ of tested samples shown in Figure 3 was based on the best results from the 0.1 to $100 \mu \mathrm{g}$ range (data not shown). In Con A-stimulated splenocytes, only sample \#4 showed significant effects; the rest of samples had no effect. In case of LPS-stimulated proliferation, samples \#4 and \#5 were active. 


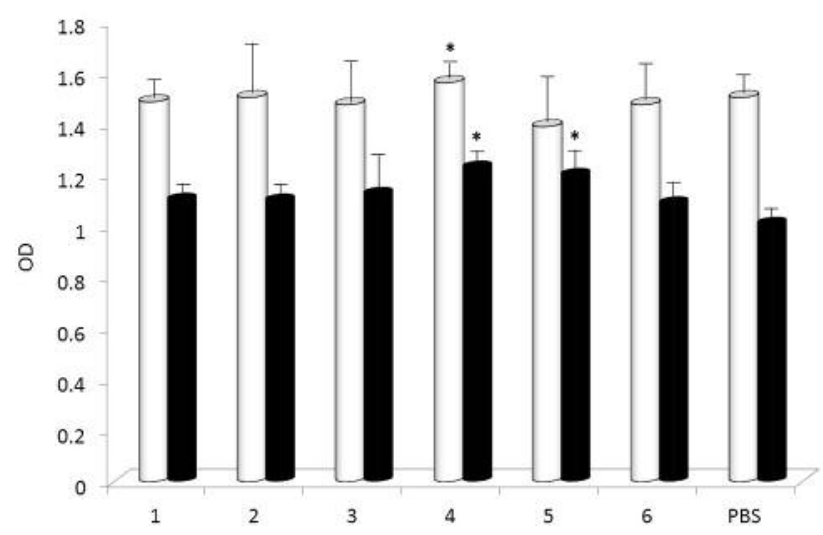

Figure 3. Administered samples affect concanavalin A (Con A)-induced proliferation of $T$ lymphocytes (white column) and lipopolysaccharide (LPS)-induced proliferation of B lymphocytes (black column). Each value represents the mean $\pm S D$. *Represents significant differences between control and experimental samples at $p \leq 0.05$ level. OD, Optical density.

In an activated macrophage assay, we found significant stimulation of both IL-10 and TNF- $\alpha$ cytokines by all samples except \#2 (Figure 4A and B). In several samples, the stimulation was the same or even strongly exceeded that of LPS.

In the next set of experiments, we focused on NK cells. All samples (except \#2) significantly increased the activity of NK cells (Figure 5). Only one of the three tested effectortarget ratios is shown. The effects, however, of the 10:1 and 100:1 ratios were identical (data not shown).

The protective effects of fucoidans were supported by findings that feeding with no-commercial samples affected relative portions of early phases of apoptosis in spleen cells (Figure 6). Samples \#1 and \#5 showed significant effects, while the remaining samples had no effect.

Finally, we evaluated the effects of tested samples on cancer development. We used mice challenged with Ptas64 mammary tumors. These experiments were also repeated with LPS-free samples with identical results (data not shown). Our data, summarized in Figure 7, show significant lowering of tumor growth by samples \#1, \#3, \#4 and \#5.

\section{Discussion}

Fucoidans are mostly isolated from seaweed. As each seaweed species comprises a unique fucoidan, the literature evaluating their biological effects often offers contradictory results. When directly compared, the immunological effects differ among the individual samples (19). The study's objective was to compare immunomodulatory activity of
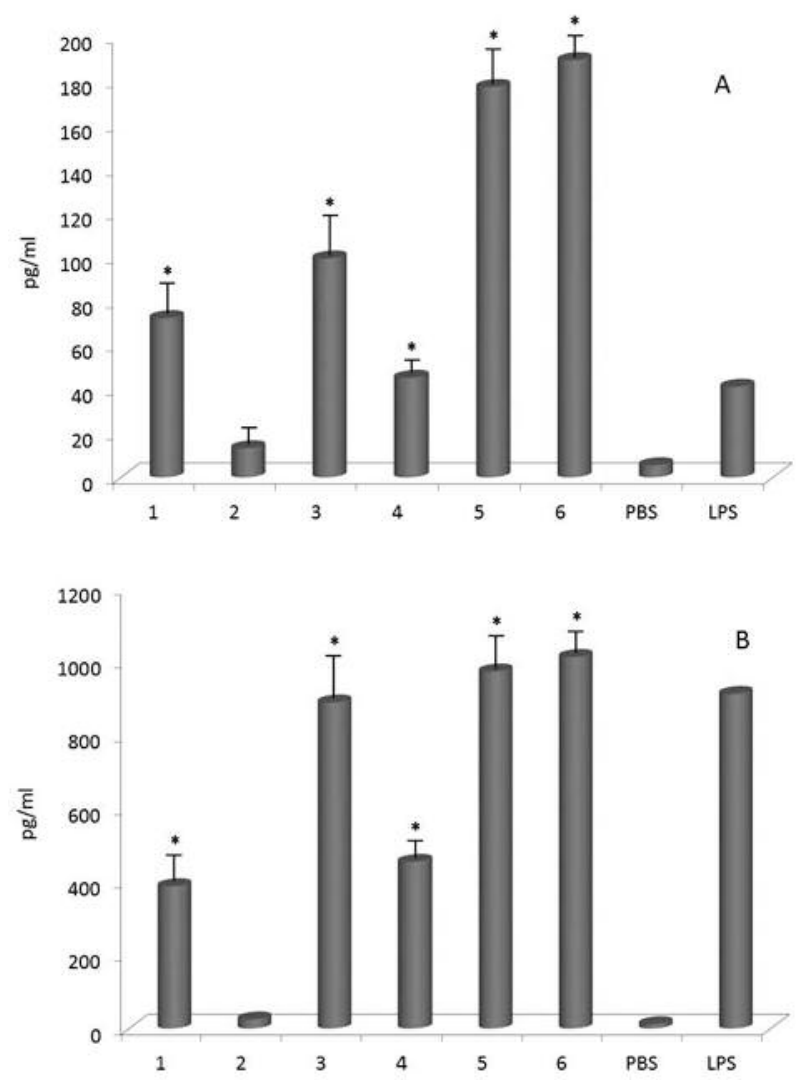

Figure 4. Administered samples affect interleukin (IL)-10 (A) and tumor necrosis factor (TNF)- $\alpha(B)$ production by activated macrophages against phosphate-buffered saline (PBS) and lipopolysaccharide (LPS). Each value represents the mean $\pm S D$. *Represents significant differences between control and experimental samples at $p \leq 0.05$ level.

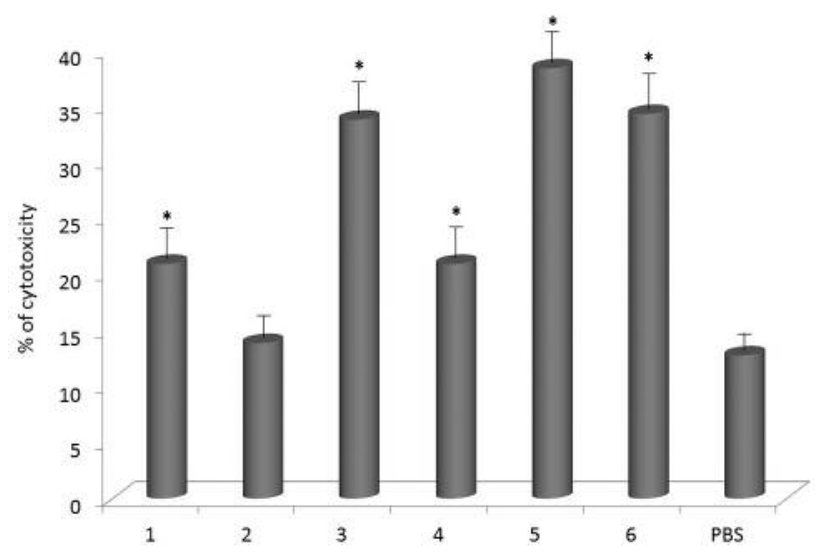

Figure 5. Administered samples affect NK cell activity against phosphate-buffered saline (PBS). A ratio of 50:1 was used. Each value represents the mean $\pm S D$. *Represents significant differences between control and experimental samples at $p \leq 0.05$ level. 


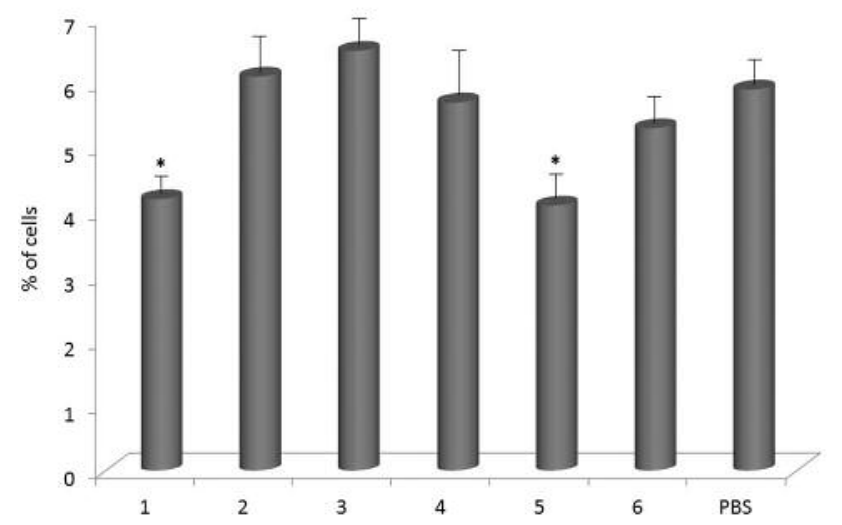

Figure 6. Administered samples affect relative portions of early phases of apoptosis in spleen cells against phosphate-buffered saline (PBS). Each value represents the mean $\pm S D$. *Represents significant differences between control and experimental samples at $p \leq 0.05$ level.

several fucoidan samples. We compared isolated fucoidans with commercial samples that contained either fucoidan alone or in combination with other molecules. In each case, we weighted the content of the capsule and calculated the dose of fucoidan, therefore eliminating possible errors due to the inert material in the capsule.

Fucoidans have a variety of biological functions (20), including mobilization of progenitor cells (21), stimulation of dendritic cells and radioprotection of bone marrow cells (22). A wide range of findings led to studies on proviral loads in humans with T-lymphotropic virus type-1. The results showed inhibition of cell-to-cell transmission and a $42 \%$ proviral load (23). Our previous study showed strong in vivo activity of fucoidan, which was comparable to that of mushroom- or yeast-derived glucans (24).

As fucoidans are known for their stimulation of phagocytosis (15), we employed synthetic microspheres known for minimum spontaneous adhesion to the cell surface and showed stimulation of internalization. A different situation was found, however, in evaluating the effects of fucoidans on antibody response. All samples were active, suggesting that these molecules can influence the cellular and humoral branch of immunity differently. Recent clinical trials examining the effects on antibody production in subjects over 60 years of age showed that both the antibody titers and NK cell activity were affected (25). Our study clearly demonstrated the effect on phagocytosis, whereas antibody and cytokine secretion confirmed previously published data further supporting the broad spectrum of fucoidans' reactivity.

Fucoidan-containing food supplements have been traditionally used in cancer patients in China, Korea and Japan. Some studies showed effects on apoptosis (14), which we confirmed. Direct mechanisms of anticancer effects are

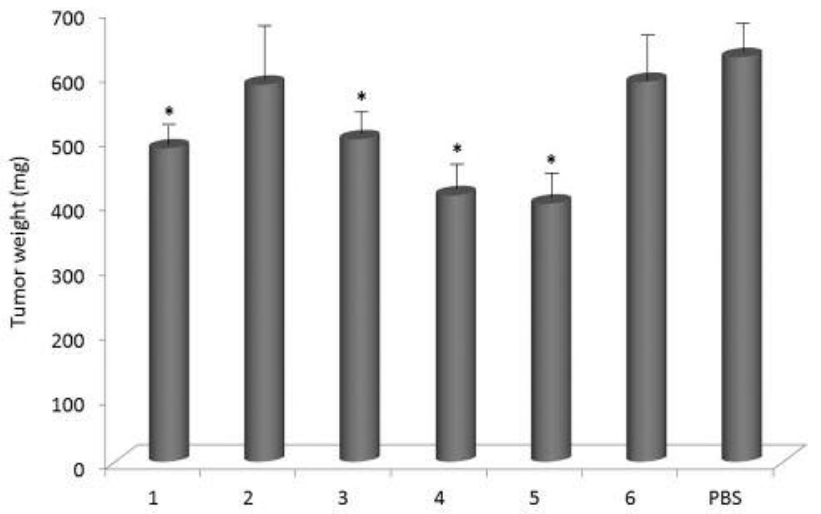

Figure 7. Administered samples on the therapy of Balb/c mice with Ptas64 mammary carcinoma against phosphate-buffered saline (PBS). Data from three independent experiments are shown. For each experiment, groups of three mice were tested for a response to therapy as indicated by the weight of tumors after two weeks of supplementation. Each value represents the mean $\pm S D$. *Represents significant differences between control and experimental samples at $p \leq 0.05$ level.

not known; however, activation of NK cells (also found in our study) and indirect stimulation of immune system are likely to occur. As fucoidans are similarly effective after intraperitoneal, intravenous and oral application, there is a potential for clinical practice. A comprehensive review of anticancer effects of fucoidans in preclinical development has been previously published by Kwak (26).

Our study used both isolated fucoidans and commercial samples, sometimes in a complex with other potentially active substances. From the presented results, it is clear that fucoidans have significant biological activities. Only some of our samples influenced all reactions and rarely all samples affected one tested reaction. The most active samples were pure fucoidans (samples \#1, \#4 and \#5), followed by a Fucoidz combo (sample \#3). Addition of more molecules to the same fucoidan as \#3 lowered the effects obtained (sample \#2). In addition, samples \#5 and \#6 showed dose-dependent action. From our results, it is not possible to conclude if addition of other biological substances lowers the effects of tested fucoidans. At the same time, our results do not provide evidence for any improvement as well. Additional experiments focusing on purified and substantially characterized fucoidans, as well as possible mechanisms of action, are currently under way.

\section{References}

1 Berteau O and Mulloy B: Sulfated fucans, fresh perspectives: Structures, functions, and biological properties of sulfated fucans and an overview of enzymes active toward this class of polysaccharide. Glycobiology 13(6): 29R-40R, 2003. 
2 Kannan RR, Arumugam R and Anantharaman P: Pharmaceutical potential of a fucoidan-like sulphated polysaccharide isolated from halodule pinifolia. Int J Biol Macromol 62: 30-34, 2013.

3 Lean QI and Ying QY: Fucoidan extracts ameliorate acute colitis. PLoS One 10(6): e0128453, 2015.

4 Yamamoto I, Takahashi M, Tamura E, Maruyama H and Mori $\mathrm{H}$ : Antitumor activity of edible marine algae: Effect of crude fucoidan fractions prepared from edible brown seaweeds against 1-1210 leukemia. In: Eleventh international seaweed symposium: Proceedings of the eleventh international seaweed symposium, held in qingdao, people's republic of china, June 19-25, 1983. Bird CJ and Ragan MA (eds.). Springer Netherlands: Dordrecht, pp. 145-148, 1984.

5 Maruyama $\mathrm{H}$, Tamauchi $\mathrm{H}$, Iizuka $\mathrm{M}$ and Nakano $\mathrm{T}$ : The role of NK cells in antitumor activity of dietary fucoidan from undaria pinnatifida sporophylls (mekabu). Planta Med 72(15): 1415$1417,2006$.

6 Fitton JH: Therapies from fucoidan; multifunctional marine polymers. Mar Drugs 9(10): 1731-1760, 2011.

7 Pomin VH: Fucanomics and galactanomics: Current status in drug discovery, mechanisms of action and role of the welldefined structures. Biochim Biophys Acta 1820(12): 1971-1979, 2012.

8 Park SB, Chun KR, Kim JK, Suk K, Jung YM and Lee WH: The differential effect of high and low molecular weight fucoidans on the severity of collagen-induced arthritis in mice. Phytother Res 24(9): 1384-1391, 2010.

9 Jang JY, Moon SY and Joo HG: Differential effects of fucoidans with low and high molecular weight on the viability and function of spleen cells. Food Chem Toxicol 68: 234-238, 2014.

10 Yang Q, Yang R, Li M, Zhou Q, Liang X and Elmada ZC: Effects of dietary fucoidan on the blood constituents, antioxidation and innate immunity of juvenile yellow catfish (pelteobagrus fulvidraco). Fish Shellfish Immunol 41(2): 264 270,2014

11 Jin JO and Yu Q: Fucoidan delays apoptosis and induces proinflammatory cytokine production in human neutrophils. Int $\mathrm{J}$ Biol Macromol 73: 65-71, 2015.

12 Jin JO, Zhang W, Du JY, Wong KW, Oda T and Yu Q: Fucoidan can function as an adjuvant in vivo to enhance dendritic cell maturation and function and promote antigen-specific $\mathrm{T}$ cell immune responses. PLoS One 9(6): e99396, 2014.

$13 \mathrm{Kim}$ SY and Joo HG: Evaluation of adjuvant effects of fucoidan for improving vaccine efficacy. J Vet Sci 16(2): 145-150, 2015.

14 Senthilkumar K, Manivasagan P, Venkatesan J and Kim SK: Brown seaweed fucoidan: Biological activity and apoptosis, growth signaling mechanism in cancer. Int J Biol Macromol 60: 366-374, 2013.
15 Anisimova NY, Ustyuzhanina NE, Donenko FV, Bilan MI, Ushakova NA, Usov AI, Nifantiev NE and Kiselevskiy MV: Influence of fucoidans and their derivatives on antitumor and phagocytic activity of human blood leucocytes. Biochemistry (Mosc) 80(7): 925-933, 2015.

16 Vetvicka V, Fornusek L, Kopecek J, Kaminkova J, Kasparek L and Vranova M: Phagocytosis of human blood leukocytes: A simple micromethod. Immunol Lett 5(2): 97-100, 1982.

17 Vetvicka V, Holub M, Kovaru H, Siman P and Kovaru F: Alphafetoprotein and phagocytosis in athymic nude mice. Immunol Lett 19(2): 95-98, 1988 .

18 Vetvicka V and Yvin JC: Effects of marine beta-1,3 glucan on immune reactions. Int Immunopharmacol 4(6): 721-730, 2004.

19 Zhang W, Oda T, Yu Q and Jin JO: Fucoidan from macrocystis pyrifera has powerful immune-modulatory effects compared to three other fucoidans. Mar Drugs 13(3): 1084-1104, 2015.

20 Choi EM, Kim AJ, Kim YO and Hwang JK: Immunomodulating activity of arabinogalactan and fucoidan in vitro. J Med Food 8(4): 446-453, 2005.

21 Frenette PS and Weiss L: Sulfated glycans induce rapid hematopoietic progenitor cell mobilization: Evidence for selectin-dependent and independent mechanisms. Blood 96(7): 2460-2468, 2000.

22 Byon YY, Kim MH, Yoo ES, Hwang KK, Jee Y, Shin T and Joo HG: Radioprotective effects of fucoidan on bone marrow cells: Improvement of the cell survival and immunoreactivity. J Vet Sci 9(4): 359-365, 2008.

23 Araya N, Takahashi K, Sato T, Nakamura T, Sawa C, Hasegawa D, Ando H, Aratani S, Yagishita N, Fujii R, Oka H, Nishioka K, Nakajima T, Mori N and Yamano Y: Fucoidan therapy decreases the proviral load in patients with human T-lymphotropic virus type1-associated neurological disease. Antivir Ther 16(1): 89-98, 2011.

24 Vetvicka V and Fusek M: Cathepsin D: Autoantibody profiling as a diagnostic marker for cancers. World J Clin Oncol 4(1): 13, 2013

25 Negishi H, Mori M, Mori H and Yamori Y: Supplementation of elderly Japanese men and women with fucoidan from seaweed increases immune responses to seasonal influenza vaccination. J Nutr 143(11): 1794-1798, 2013.

26 Kwak JY: Fucoidan as a marine anticancer agent in preclinical development. Mar Drugs 12(2): 851-870, 2014. 